\title{
EL PROCESO CIVILIZATORIO Y SU PRESENCIA EN LA HISTORIOGRAFÍA CHIHUAHUENSE: MODELOS, TIPOLOGÍAS Y HERENCIAS
}

MARIO ALEJANDRO DOMÍNGUEZ CRUZ ${ }^{1}$

\section{RESUMEN}

1 $n$ este texto se pone en contexto el llamado proceso civilizatorio en la historiografía chihuahuense del siglo XX. Utilizando las posturas del sociólogo Norbert Elias dentro de su obra El proceso de la civilización, se pretende demostrar cómo las interpretaciones sobre la historia mexicana, y en particular de Chihuahua, operan bajo una estructura que manifiesta la confrontación entre la civilización y la barbarie. Las obras a estudiar son producciones intelectuales de principio y mediados de siglo que comparten elementos historiográficos que las hacen parecidas, a lo que bien podría responder a un modelo, tipología o herencia. A su vez, se quiere continuar la discusión académica propuesta por el historiador Luis Aboites en su artículo acerca de la historiografía de Fuentes Mares y el llamado personaje del "criollo chihuahuense," cuyo origen podría encontrarse en el proceso de la civilización. Este artículo halla su pertinencia al poner en análisis algunas de las producciones intelectuales más notorias acerca del pasado que se escribieron a principio de siglo XX en Chihuahua

1 Candidato a doctor en historia por la Universidad Autónoma de Chihuahua y la Universidad Iberoamericana CDMX. 
y encontrar relación y similitudes en obras y autores posteriores, tema poco trabajado.

Palabras clave: civilización, barbarie, modernización, proceso, historiografía.

\begin{abstract}
The present text puts in context the civilization process in the chihuahuan historiography of nineteenth century. Using arguments by Norbert Elias and his book the The civilization process, pretends prove how the interpretation about mexican history, particularly from Chihuahua, works under a structure that show the confrontation between the civilization versus barbarism. The historical books to study are intellectual productions from early twenty century that share historiography elements that make them similar, which could well respond to a model, typology or inheritance. This text wants to continue the academic discussion proposed by the historian Luis Aboites in his article about the historiography of Fuentes Mares and the called character of the "criollo chihuahuense" whose origin could be found in the process of civilization. Finally, this article finds its relevance by putting into analysis some of the most notorious intellectual productions about the past that were written at the beginning of the nineteenth century in Chihuahua and finding a relationship and similarities in later works and authors.
\end{abstract}

Keywords: civilization, barbarism, modernization, process, historiography.

\title{
INTRODUCCIÓN
}

La historia contemporánea de México ha sido objeto de diversas formas de interpretación, a pesar de la pluralidad de opiniones la mayoría concuerda que tras la independencia de España, surgieron diferentes proyectos políticos opuestos que encaminaron la naciente nación a la lucha armada. En gran parte del siglo XIX, li- 
berales y conservadores mexicanos se empecinaron a ejecutar sus proyectos políticos, los cuales llevarían a varias guerras, entre las principales La Guerra de Reforma y la Intervención Francesa. De estos últimos, el bando liberal salió triunfante, y desde entonces, se dedicó a implementar su proyecto modernizador con miras de civilizar la precaria nación mexicana.

El estudio del siglo XIX mexicano lleva irremediablemente a pensarlo como intrincado camino para alcanzar a las naciones más avanzadas del orbe civilizado. El proyecto liberal mexicano pretendía desde lo político, económico y social, establecer reformas que abrieran el paso a dicho objetivo. El historiador Xavier Guerra, en su libro Del antiguo régimen a la Revolución, escribió de un liberalismo modernizante a favor del fortalecimiento de un Estado democrático cuya base sería la creación del individuo y su propiedad, idea que se remonta hasta la constitución de Cádiz (Guerra, 1989: 302). Al igual, el historiador Guillermo Zermeño dentro de su reciente libro titulado Historias conceptuales argumenta que los liberales mexicanos apuntaban a modernizar y civilizar la nación mexicana, erradicando la antigua sociedad corporativista y estamental heredada de la colonia, e implantando el espécimen de los individuos políticos (ciudadanos) de los gobiernos representativos (Zermeño, 2017: 205). Ambos responden a una tradición historiográfica sólida y fundamentada que los hace coincidir.

Los citados textos abordan el problema de modernización mexicana desde una mirada a partir de lo nacional, o bien, centro de México. Ambas posturas son aceptadas por el medio académico contemporáneo y se tienen como modelos de interpretación. En ocasiones se parte desde ellas para iniciar un trabajo de investigación. Dicho esto, interesa saber aquí cómo el citado proceso modernizador del siglo XIX fue estudiado y abordado desde la perspectiva de algunos historiadores locales chihuahuenses del siglo XX, al analizarlos, se tratará de encontrar lo que comparten y tienen en común.

Para el caso de la región de Chihuahua, si bien la guerra contra los conservadores y el triunfo sobre ellos es un factor de importancia para discutir y democratizar la idea de modernidad y 
civilidad para los intelectuales locales, se anticipa que la llamada Guerra contra los Bárbaros, acontecida a lo largo del siglo XIX, es un factor aún más determinante y endémico para pensar el proceso de modernización. El actual artículo expone el referido proceso en el Chihuahua decimonónico, trayendo al análisis las ideas del sociólogo Norbert Elias en su texto titulado El proceso civilizatorio. Con ello se busca demostrar la existencia del proceso, mismo que fue plasmado en los relatos históricos chihuahuenses de inicio del siglo XX, como una tipología trascendente de la historiografía local conformada por los binomios opuestos de "civilización" y "barbarie".

Previas propuestas, tales como la del historiador Carlos J. Alonso y su artículo llamado "Civilización y Barbarie", apuntan que la mencionada dicotomía forma la base argumentativa y narrativa de los relatos históricos hispanoamericanos, lo que sin duda las siguientes líneas reforzarán. Vistos desde algunos casos de estudios en Latinoamérica, los conceptos de “civilización” y "barbarie”, indica Alonso, se configuran como categorías fundamentales y totalizadoras de la realidad americana (Alonso, 1989: 256-257). La lucha entre ambas funciona como un tropo narrativo, cuya característica es que son inseparables y su confrontación gira hacia la supuesta supresión del otro. No obstante, ninguna puede existir sin la otra, ambas se complementan (Alonso, 1989: 261-262).

Para continuar, se considera que la teoría de Norbert Elias es muy conveniente para este trabajo de corte historiográfico. Esto, debido a que para Elias la idea de civilización es ante todo efecto de un proceso histórico. Gran parte de su obra intelectual pone en perspectiva los elementos psicológicos y sociales de la humanidad desde su genealogía y su respectivo desarrollo diacrónico. Dimensionar así la civilización, más allá de lo sincrónico, colabora a rastrear su expansión además de posibilitar plasmarla y argumentarla de forma histórica. 


\section{EL PROCESO CIVILIZATORIO Y SU PRESENCIA EN EL CHIHUAHUA DEL SIGLO XIX}

Los relatos sobre historia de Chihuahua acerca del siglo XIX en relación con las batallas entre liberales y conservadores y sobre todo contra los apaches, además de mostrar posicionamientos políticos distintos y antagónicos con los primeros (liberalismo contra conservadurismo), con los segundos se expone una confrontación directa entre naciones y formas de vida totalmente distintas (sedentarismo contra nomadismo). También, ambos casos fueron causa de la manifestación física de un proceso de modernización.

El liberalismo mexicano dio el golpe final a su rival político con la derrota del Segundo Imperio Mexicano en la ciudad de Querétaro en el año de 1867. No obstante, el grupo de liberales chihuahuenses tuvo que hacerse cargo del problema regional de la apachería. Desde el fin del Virreinato de la Nueva España y la desaparición de los cuarteles fronterizos llamados presidios, el nomadismo de los grupos apaches se acrecentó, llevando como consecuencia a la confrontación armada y cuyo fin se lograría hasta la década de 1880 (León y González, 2000: 153).

La guerra contra los apaches fue entendida de la siguiente manera: en una esquina se tenía al mundo civilizado, mismo que en algún momento fue representado por el español, sus leyes e instituciones, aquellos que por medio del presidio y las pensiones semanales trataron de asentar al nómada: civilizarlo. Próximo y en el mismo lugar se tenía al mexicano decimonónico, quien en su intento por modernizarse vio en el nómada septentrional un gran impedimento para su empresa. La forma de vida del indio apache, en ojos del mexicano decimonónico, impedía la vida civilizada fundamentada en el trabajo y la paz. En la otra esquina se tenía al nómada, quien por su contraparte además de enemigo no pasaba de colocarse en la categoría de bárbaro. En pocas palabras, para el civilizado el apache era un ser vil e ignorante, entregado a sus pasiones y emociones, quien debido a su naturaleza precaria lo único que tenía por hacer era robar y matar. Poseedor de una forma de vida itinerante, fue muy renuente y desconfiado a los 
intentos sistemáticos de sedentarización occidental. Palabras de los mexicanos del siglo XIX acerca de los apaches:

Es extraordinaria la velocidad con que huyen después de ejecutado un crecido robo, cuando regresan a su país, escalando montañas, atravesando desiertos sin agua y valiéndose de mil estratagemas para eludir los golpes de los ofendidos. A la larga distancia dejan siempre sobre sus huellas dos o tres indios en los caballos más ligeros, para que den oportuno aviso de los peligros. Cuando temen la persecución de fuerzas superiores, matan los animales que llevan y escapan en las mejores bestias, que últimamente viene a matar también en el caso de que los alcancen asegurando su vida en las asperezas y breñales de los montes. Si les persiguen fuerzas inferiores, las esperan en un desfiladero y cometen una segunda matanza (Herrera y Cicero, 1895: 59-60).

Al considerar la polaridad del ambiente en la zona norte de México: los binomios opuestos permitieron imponer un ambiente hostil y de guerra; unos se presentaban a sí mismos como civilizados y los otros eran presentados como cruentos, bárbaros y salvajes. Pero ¿qué es ser civilizado? ¿Qué diferencia hay entre la civilización y la barbarie? El sociólogo Norbert Elias, en su obra titulada El proceso de la civilización considera que la transformación y refinamiento de los modales y conductas del hombre europeo son consecuencia de un largo proceso histórico, aseverando como conclusión que la idea de civilizado y civilización es resultado de la autoconciencia de los pueblos europeos (Elias, 2016: 83). El comportarse e identificarse como un ser civilizado es actuar conforme a las formas y actitudes de las culturas francesa, inglesa o alemana, principalmente. La civilización y comportamiento civilizado es, como se dijo antes, un producto procesual e histórico propiamente europeo, no es natural, universal ni general. Se le deben a occidente las pautas que marcan la discrepancia entre el comportamiento civilizado o barbárico. Dentro de la obra es posible leer al respecto: 
Pero si se trata de comprobar cuál es, en realidad, la función general que cumple el concepto de 'civilización' y cuál es la generalidad que se pretende designar con estas acciones y actitudes humanas al agruparlas bajo el término de 'civilizadas', llegamos a una conclusión muy simple: este concepto expresa la autoconciencia de occidente. También podría denominarse 'conciencia nacional'. El concepto resume todo aquello que la sociedad occidental de los últimos dos o tres siglos cree llevar de ventaja a las sociedades anteriores o a las contemporáneas... el grado alcanzado por su técnica, sus modales, el desarrollo de sus conocimientos científicos, su concepción del mundo y muchas otras cosas (Elias, 2016: 83).

Entonces, civilización corresponde y refiere al proceso de refinamiento de los modales y conductas de los seres humanos a lo largo del paso del tiempo en un determinado punto sobre el globo terráqueo. Es el transitar de un estado primitivo e instintivo a uno más sofisticado y racional. Una actitud civilizada en una persona se manifiesta, según el trabajo de Elias, de formas tan sencillas como las que van desde la regulación de gestos corporales y de emociones, la forma de sentarse en un banco, reírse de tal o cual forma, hasta la manera en que se toman y utilizan los cubiertos en la mesa. El porte y uso de dichos signos sociales determinan qué grupo social, comunidad o persona es o no, civilizada.

La formación de los modales civilizados en el corazón de la cultura europea, requirió la construcción discursiva del comportamiento correcto y bien visto, recopilado en extensos manuales. Aludiendo al contenido de la investigación de Norbert Elias, uno de los textos más importantes que forjaron los modales de una persona civilizada fue De civilitate morum puerilium de Erasmo de Rotterdam, que según el sociólogo ha sido objeto de más de 130 ediciones (Elias, 2016: 131). La lectura del manual de Erasmo pretendía formar la actitud de los modales de los jóvenes nobles (Elias, 2016: 132). De tal manera que dicho texto y otros tantos pasaron a ser lectura obligada en los altos círculos sociales europeos, y desde ahí, permearon e influyeron a los miembros de los grupos estamentales inferiores. 
Tales gestos corporales se complejizaron por medio del paso de las generaciones, las actitudes civilizadas fueron aceptadas en todos los estratos sociales occidentales. Se marcó la diferencia entre un ser civilizado y no civilizado. Como resultado de un proceso histórico de siglos, la civilización terminó por instaurar en el individuo y grupos sociales una rígida estructura de autorregulaciones de pasiones y emociones. Aquella persona que se decía civilizada en primer lugar era porque lograba controlar sus más naturales, viscerales y violentos sentires por medio de repulsiones, culpas y penas formadas socialmente (Elias, 2016: 541).

A la par, una sociedad que se tiene por civilizada es aquella cuya estructura ha alcanzado la formación de un Estado fuerte y altamente regulado por medio de instituciones que coaccionan y obligan a los individuos a autorregularse. Estas instituciones coercitivas (policía, ejército, guardias) poseen la capacidad y monopolio de la violencia para lograr el objetivo (Elias, 2016: 544). Un paso dentro del proceso de civilización se da cuando el individuo, debido a la complejidad de las relaciones sociales y de trabajo, renuncia a su derecho de protegerse y defenderse por sí mismo, y termina cediéndolo a la estructura que compone el Estado (Elias, 2016: 567).

Los argumentos de Elias en el caso del Chihuahua de finales del siglo XIX se observan, por ejemplo, en la existencia de un Estado mexicano, representado por el gobierno liberal y federal del centro del país; y desde la región, una elite liberal con modales occidentalizados que encabezaba el gobierno estatal. Este mismo Estado, con pretensiones civilizatorias, tenía a su disposición el monopolio de la violencia, personificado en los cuerpos militares destinados a combatir a los apaches. En los archivos relacionados con el tema de la guerra contra los nómadas, abundan las proclamas hechas por el gobierno del estado de Chihuahua, donde autoriza la organización de patrullas y la portación y uso de armas a los vecinos de los pueblos agraviados por la apachería, una de ellas fue la enviada a las autoridades del Carrizal en el año de $1870{ }^{2}$ En

2 AHSECULT, Área de Colecciones Especiales, Archivo del Carrizal, Rollo no. 11, 5 de marzo de 1870. 
segundo lugar, se encontraban los grupos nómadas, definidos por su rebeldía y desconfianza ante las instituciones y cualidades de los grupos civilizados, con una forma de vida adquirida a través de un proceso de duración de siglos y endémica a la región donde habitaban.

En cuanto a las formas de vida de los dos grupos, se tenía por un lado al chihuahuense, individuo que pertenecía a una estructura social altamente segmentada y especializada a partir de sus actividades laborales, encabezada por una elite económica y política occidentalizada, cuyos miembros eran educados en los Estados Unidos o Europa (Guerra, 1988: 355); y por el otro lado, en cuanto al medio rural, se tenía a una comunidad de rancheros, quienes debido a la proximidad con la frontera de los Estados Unidos, interactuaban y adoptaban la cultura y forma de vida norteamericana (Dale, 2001: 148-149). La vida civilizada de dichos sujetos históricos: regulada, coercitiva, reflexiva y moldeada por medio del pudor, disgusto y la culpa, se vio claramente en conflicto con las costumbres de los nómadas. Vestidos con pieles, semidesnudos, viviendo en casas desmontables, cocinando y comiendo en la intemperie con el más mínimo grado de sofisticación y con el menor grado de recato en sus modales, a los ojos de los civilizados la vida nómada parecía despreciable y digna de animales salvajes.

Otro de los apoyos utilizados por la civilización occidental para distinguirse de la otredad, es el llamado uso de la racionalización del comportamiento. Esto se refiere a la autorregularización y limitación de la psique humana, es decir, que el sujeto antes de actuar considere a profundidad las consecuencias de sus actos. Bajo tal supuesto, una persona civilizada trata de poner sobre perspectiva cada decisión tomada y, ante una agresión o estímulo, reprende sus instintos e impulsos; tomará la vía de la reflexión, diálogo y conversación para solucionar cualquier tipo de disputa. Contraparte, un comportamiento barbárico se define por acciones impulsivas e instintivas que no contemplan sus efectos a largo plazo (Elias, 2016: 580).

Es posible discernir en los discursos oficiales del estado de Chihuahua y su elite gobernante, el recurso de justificar la con- 
dición de barbarie en los indios nómadas por medio de la falta de racionalización en sus acciones. Para el chihuahuense decimonónico, el apache era un ser violento totalmente entregado a sus pasiones y que solo tenía por forma de vida asaltar y matar. La posibilidad de diálogo entre el mexicano y el nómada llegó al punto de ser inviable puesto que la naturaleza de los segundos era supuestamente primitiva y salvaje. Ante la adversidad, el mexicano vio el aniquilamiento como única posibilidad de solución al conflicto. Al no ser considerados seres pensantes y racionales, fueron reducidos al rango de bestias. Aquí pues, una nota del diario El Monitor Republicano del año de 1881 haciendo referencia a una publicación del Periódico Oficial del Estado de Chihuahua, en ella se dice:

Los bárbaros.- Dice el Periódico Oficial del Estado de Chihuahua: Se encuentran aún a las inmediaciones de Casas Grandes esperando que se les conceda la paz. Ni el gobierno ni el jefe de las fuerzas federales pueden creer en la buena fe de esas hordas de asesinos cuya perfidia es demasiado conocida. Por tal motivo, se han estado concentrado las fuerzas federales y las del estado en los puntos más convenientes...

Los rastros desoladores que han dejado los salvajes en nuestra frontera y en la de la nación vecina, los innumerables asesinatos, los incontables robos, todos esos numerosísimos y trágicos episodios que desde hace mucho riegan con sangre nuestra tierra y que han causado el abatimiento y la ruina del estado, demuestran de una manera azas evidente, la desoladora verdad de que esas tribus indomables tienen un natural instinto de sangre y de robo; contra el cual ha sido impotente la civilización, y que no queda más recurso para librarse de sus males, más que exterminarlos como a fieras salvajes o dispersarlos a mucha distancia los unos de los otros... ${ }^{3}$

3 HNDM "Los bárbaros"/28 de diciembre de 1881/ El Monitor Republicano. El documento puede ser consultado en línea: www.hndm.unam.mx Las cursivas son del autor. 
Para Norbert Elias, durante el siglo XIX el proceso de la civilización tomó un curso interesante. El expansionismo europeo, por cada rincón del globo, utilizó el concepto de civilización como pretexto de sus aspiraciones colonialistas. Dicha tarea se logró a través de la coacción de instituciones complejas y de la estricta regulación del comportamiento, todo para trazar una línea entre ellos y la otredad barbárica; bajo esta distinción, lograban crear una supuesta inferioridad de los otros, imponiéndose por la ley del más fuerte (Elias, 2016: 559). El libro del proceso de la civilización acerca de la estrategia colonialista del siglo XIX:

La conciencia de la propia superioridad, la conciencia de esta 'civilización’ sirve como justificación de la dominación que ahora van a ejercer cuando menos aquellas naciones que se han convertido en conquistadoras-colonizadoras y, con ello, en una especie de clase alta para una parte considerable del mundo extra-europeo (Elias, 2016: 129).

Entendido como un proceso finiquitado, los pueblos europeos se consideraron a sí mismos como transmisores de esa civilización a otros ubicados en un nivel inferior. Fue por medio de este discernimiento que surgió la acción emprendida en contra de los indios nómadas del norte del continente americano. La occidentalización del amerindio provocó la confrontación violenta y la resistencia a las formas de vida civilizadas. Los intentos por civilizar al nómada pueden ser rastreados a través del paso del tiempo, desde el español en el virreinato hasta el mexicano en gran parte del siglo XIX. Recelando a dicha occidentalización, el apache opuso una férrea resistencia en los ambientes naturales más hostiles de América; apegados a su inmemorial estilo de vida, se dedicaron a la caza, rapiña y saqueo de las propiedades de los sedentarios. En las páginas del libro Cinco ensayos sobre la cultura material de ranchero y medieros del noroeste de Chihuahua, publicado en el 2001, la historiadora Jane Dale Llyod, escribió: 
'El progreso' civilizador del europeo, y posteriormente del criollo, requería de la occidentalización del indio nómada, de su subordinación y su sedentarización. El nómada, empeñado en conservar su forma de vida trashumante, aprendió a vivir en los límites de la colonización. Desarrolló una extraordinaria habilidad para el saqueo furtivo y la rapiña, y se convirtió en el azote de la colonización norteña (Dale, 2001: 40).

La modernización del norte de México en el siglo XIX implicaba eliminar las posibles trabas para su plenitud. El enemigo bárbaro obstaculizaba los planes de la elite liberal con miras capitalistas asentada en los grandes centros urbanos pero con alta presencia económica en zonas rurales. A lo largo del noroeste de Chihuahua la familia Terrazas-Creel se hizo de productivas haciendas y tierras, las cuales debido a su ubicación fueron blanco del constante ataque de los apaches. El libro titulado Capitalistas, caciques y revolución del historiador Mark Wasserman menciona en variadas ocasiones el acaparamiento de tierras por parte de la elite chihuahuense. Según Wasserman, de 1870 a 1898 la familia Terrazas adquirió un aproximado de ocho haciendas en la región de Galeana, zona caracterizada por su alta actividad de apachería; entre las más redituables y famosas propiedades se encontraba la Hacienda del Carmen (Wasserman, 2003: 170).

En última instancia, el plan capitalista y liberal pretendía eliminar cualquier rastro del orden tradicional y colonial basado en los vínculos solidarios, familiares y compadrazgos (Guerra, 1988: 138). Era la implementación de un nuevo modelo económico basado en el individuo y su propiedad, dejando atrás elementos de una cultura heredada, tales fueron la tierra comunal, tribus indígenas, clanes y familias (Guerra, 1988: 153). Como producto acabado, la modernización intentaba trasladar una entidad -la comunidad norteña - de un punto de rezago fundamentado en la tradición y comunidad, a uno más sofisticado, basado en las formas de vida liberales y capitalistas alcanzadas por las naciones más avanzadas del mundo (Guerra, 1988: 302). Según el historiador Guillermo Zer- 
meño, en el siglo XIX la civilidad empezó a ser entendida como un proceso. En sus palabras:

La civilización era un proceso que se podía acelerar o retardar. En Londres por ejemplo, un funcionario se preguntaba si era o no propio de la naturaleza humana que las civilizaciones, después de llegar a su cenit, pudieran luego descender 'al ocaso de la indigencia y barbarie' (Zermeño, 2017: 196).

Si por naciones desarrolladas en la época se entendían las potencias europeas (Francia, Inglaterra, Alemania) y los Estados Unidos de América, hay por tanto una pretensión del mexicano decimonónico por adoptar en totalidad la forma de vida occidental. Las características que posee esta manera de vivir implican, como lo argumentó Norbert Elias, en la segmentación y especialización rigurosa de la sociedad, el desarrollo de mecanismo de auto-coacción y formas muy específicas y refinadas del comportamiento del individuo en sociedad. Al considerar lo anterior es posible encontrar una clara y estrecha relación entre el proceso de modernización liberal mexicano y el proceso de civilización de occidente. Modernizar la nación mexicana era imitar a las naciones más avanzadas, por tanto, era adoptar la vida civilizada.

\section{EL PROCESO CIVILIZATORIO Y SU PRESENCIA EN LA HISTORIOGRAFÍA DE LOS ALBORES DEL SIGLO XX}

Los textos sobre historia de Chihuahua elaborados en los inicios del siglo XX contienen la narración de un proceso inferido por sus autores, en ellos se muestra el andar de un colectivo entre etapas temporales. Ahí está narrado el paso de una época a otra, de lo antiguo a lo moderno; dentro está el proceso modernizador y civilizador de la región que se enfrentó a la barbarie.

Son tres reproducciones narrativas del pasado las que por el momento se trabajan. Los tres textos son producción intelectual de principios de siglo XX y encierran en sus palabras el imaginario de la época y las ideas de cómo fue el pasado que los condujo 
justo al momento en el que vivían. Escritas a petición de la elite local en la primera década del siglo XX, son estas las Reseñas históricas del estado de Chihuahua (1905) de Ponce de León, El Álbum Directorio del estado de Chihuahua (1904) de Federico García y Alva y Las Memorias del Coronel Joaquín Terrazas (1905).

Los mencionados textos son entendidos como artefactos literario-poéticos e ideológicos; un producto social y subjetivo. Adentrarse a sus características requiere identificar su lugar social de producción, esto último en el sentido más allegado a las posturas de Michel de Certeau y la llamada operación historiográfica (De Certeau, 2010: 68). Según De Certeau, todo historiador comienza su trabajo profesional desde un llamado lugar social, que resulta ser condiciones previas de carácter social, ideológico y estructural que motivan e influyen en el trabajo intelectual del autor. Además, existen otros factores que influyen en el resultado de la narración histórica muy a pesar de su compromiso epistemológico. Las condiciones que permiten el desarrollo de lo que De Certeau llama la operación historiográfica son, primero, las fuentes históricas y materia prima para la construcción del relato; segundo, las técnicas metodológicas y formas de trabajar, o en palabras que bien podrían ser de De Certeau, los saberes; por último, el francés identifica un elemento recóndito y oculto: la subjetividad del autor. Desde su punto de vista estos elementos son necesarios para el desarrollo del quehacer historiográfico. Un último factor que identifica Michel de Certeau, es el público a quien va dirigida la obra en cuestión. Para él, por ejemplo, la obra histórica crítica y académica tiene por destinatario no al público en general, sino a un selecto grupo de colegas, quienes monopolizan el saber historiográfico, además de ser estos quienes deciden si el mencionado texto cumple con los requerimientos necesarios para ser considerado aceptable. Existe pues un lugar de producción o enunciación y un público a quien se escribe.

Al contextualizar el origen de las obras de historia de Chihuahua en discusión, estas se pueden entender como el intento de las elites locales por generar una identidad estatal o regional por medio del pasado. A finales del siglo XIX y principios del XX, 
en México, gobiernos y elites estatales y nacionales dieron a sus intelectuales la encomienda de obras históricas que rescataran el glorioso pasado de México. Cabe mencionar la monumental obra de México a través de los siglos, del liberal Vicente Riva Palacio. $\mathrm{Su}$ escritura resultó un encargo personal del presidente Manuel González al escritor Riva Palacio, la cual inicialmente buscaba tan solo rescatar los sucesos de la Guerra de Intervención de Estados Unidos hasta la Guerra de Reforma. Para el presidente, la escritura del texto pretendía ser, además de un esfuerzo intelectual para crear identidad nacional, un habilidoso movimiento para alejar a Riva Palacio de la política quien por entonces fungía como diputado federal (Cosio, 1999: 631). A pesar de los roces con Manuel González y las varias trabas puestas al coordinador de la obra, México a través de los siglos pudo ver la luz en el año de 1884. La narración no solo se limitó a lo ocurrido durante las guerras de intervenciones a mediados del siglo XIX, por el contrario, se consolidó como una extensa obra de cinco volúmenes que rescataba la historia de México comenzando por la época prehispánica (Cosio, 1999: 635). Como consecuencia, el texto de Riva Palacio se volvió en el relato de historia de México por excelencia, siendo además un símbolo de la identidad nacional.

Asimismo, en dicho contexto histórico, puede mencionarse a otro intelectual cuyas obras presentan paralelismos con lo realizado por los intelectuales chihuahuenses; nada menos que el positivista Justo Sierra. En el gran repertorio de sus obras, se dedicó a ensalzar el proyecto liberal decimonónico y la figura central del régimen en vigencia: Porfirio Díaz. Ejemplos evidentes pueden ser sus ensayos titulados La evolución política del pueblo mexicano y México, su evolución social, y cuyos escritos resguardan la figura del presidente Díaz como el caudillo de fuerte personalidad que pacificó el país y permitió su progreso gradual (Del Arenal, 2006: 36). No se puede dejar sin mencionar su célebre libro Juárez, su obra y su tiempo como respuesta a la polémica obra de Francisco Bulnes titulada El verdadero Juárez y la verdad sobre la Intervención y el Imperio, siendo el libro de Sierra una contestación del 
liberalismo oficial, cuya meta era rescatar la imagen de una de las principales figuras ideológicas del porfiriato (Del Arenal, 2006: 38).

En cuanto a la producción de estas obras en lo regional, se cuenta con las Reseñas históricas del estado de Chihuahua escritas en el año de 1905 por el chihuahuense José María Ponce de León. Nacido en el mineral de Uruachi en 1878 y egresado de El Instituto Científico y Literario de la ciudad de Chihuahua, quien sirvió gran parte de su vida a la administración pública siendo secretario de gobierno. Su texto sobre la historia de Chihuahua en principio fue encomendado y financiado por el famoso miembro de la familia Terrazas-Creel, Enrique C. Creel, durante su administración como gobernador del estado de Chihuahua. Ante tales datos, es posible discernir la obra de Ponce de León como un producto por y para la elite local, escrito para complacerlos y su contenido intentó lograrlo.

El historiador Ponce de León recurrió principalmente a obras y documentos de naturaleza institucional para elaborar su obra. Citó fuentes como Las noticias de las misiones de P. Pascual, el Alzamiento de los indios tarahumaras, la Historia de la compañía de Jesús del P. Alegre, El Testimonio escrito por el P. (jesuita) Guadalajara Tarder, el Informe sobre los presidios de la Nueva Vizcaya por Berroterán, la Crónica Zacatecana de Arlegui, la Historia y conquista de la provincia de la Nueva Vizacaya de Mota Padilla, el Diccionario geográfico de Pérez Hernández, The Northern Mexican State de Bancroft (Ponce de León, 1905: 4). Al mencionarlas, las catalogó como fuentes escritas por autoridades históricas de indiscutible peso.

Comenzar el análisis de su contenido advierte de inmediato el inicio de una serie de sucesos que se fundamentan en el antagonismo de dos partes, entendidas como el hombre blanco (civilización) y el indio bárbaro (barbarie). Desde el principio, el autor introduce al gran protagonista de la trama y su enemigo, quienes gracias a su confrontación dieron los sucesos a los que llamó historia de Chihuahua. No cabe duda de la influencia del contexto social e histórico en Ponce de León. Sus Reseñas... fueron escritas 
aproximadamente veinte años después del fin de la guerra contra los bárbaros, y estos mismos dirigen en momentos su contenido.

El primero de los capítulos se llama "Los primeros habitantes", y carece de una estructura narrativa; no hay acontecimientos que posibiliten otros y se releven unos a otros. La temporalidad queda ausente, no hay historia. Lo que el autor decide hacer en el capítulo es establecer las condiciones previas con las cuales tendrá que batir el protagonista de la narración, el principal de ellos será el indio bárbaro: la nación apache. Es este personaje el enemigo a vencer, el que siempre está presente e impide a toda costa el progreso de la región. Tras la llegada del hombre blanco a territorio que más adelante se conocerá como Chihuahua es cuando comienza su relato. Al describir al enemigo, Ponce de León no dudó en hacer referencia a su hostilidad, característica que desde mucho tiempo el chihuahuense colocó en el apache. Las nociones de barbarismo en los nómadas fueron escritas y presentadas de la siguiente forma en las Reseñas...:

Esta indomable raza hostilizaba no solo a los blancos, sino que se mantenía en lucha constante con los comanches y con todas las tribus vecinas que no hablaban su propio idioma, prolongándose semejante situación hasta que en sus últimas bandas expulsadas del territorio de Chihuahua, fueron acantonadas en las reservas norteamericanas, donde van lentamente desapareciendo (Ponce de León, 1905: 10).

Tras presentar la otredad enemiga, el relato continuó ahora introduciendo al protagonista. Como si se tratara de una epopeya, introdujo al hombre blanco en un lugar hostil y lleno de adversidades. Al continuar con su estilo, exalta al hombre blanco y su virtud al punto de novelizar su travesía. La presencia de este personaje en la obra permite, ahora sí, la existencia de una trama, cuya estructura se basa en la existencia de acontecimientos que se irán relevando uno tras otro, desde el inicio hasta el fin. En el libro de Ponce de León se lee lo siguiente: 
El viaje a estos territorios del primer hombre blanco, es en verdad novelesco, relacionándose con los fabulosos relatos de Quivira y de las 'siete ciudades', que como un espejismo argentifero, atrajeron por largos años la codicia de los conquistadores, que avanzaban hacia el Norte en busca de un 'El Dorado' maravilloso, que se desvanecía a medida que extendían las fronteras septentrionales de sus dominios (Ponce de León, 1905: 13).

Las dos citas arriba muestran la existencia de dos personajes confrontados en lo que Ponce de León llama historia de Chihuahua. El indio bárbaro se muestra como un ente hostil y salvaje, cuya naturaleza lo conduce a un estado de guerra constante con sus demás vecinos. En su narración persiste el imaginario sobre el apache construido durante el siglo XIX, esto influyó y lo vuelve enemigo originario y persistente del hombre blanco a través del tiempo. El otro personaje debe de ser entendido como el europeo, cuya exploración del septentrión se debió en parte a la búsqueda de bienestar y riqueza. Es este sujeto la contraparte del bárbaro y portador del espíritu civilizado. Al realizar una genealogía, se identifica en el hombre blanco de Ponce de León al ancestro inmediato del chihuahuense de cambio de siglo. Como antecesor, también transfiere a su estirpe una tradición y cultura, encarnada en la sociedad chihuahuense y dirigida por la familia TerrazasCreel. Ambos personajes, siempre confrontados, encontraron el desenlace a su rencilla durante la década de 1880 con el llamado fin de las guerras indias.

Los apartados que continúan hacen referencia a la colonización del norte americano y la fundación de misiones en los territorios descubiertos. En estas páginas se hace mención de las rebeliones indias, entre las más importantes la de Teporaca en 1645. La revuelta es atribuida a la opresión a la que estaban sometidos los indios por parte de las autoridades virreinales y a la condición natural de indomabilidad de los indios (Ponce de León, 1905: 18). Las características del relato histórico sugieren la persistencia de una trama antagónica y de confrontación, es dual y complementa- 
ria. La perdurable amenaza del mal de los salvajes aborígenes y la pugna con su adversario, el hombre blanco, entraman la historia.

El combate señalado, entre bárbaro y civilizado, según la visión de Ponce de León, lleva a un punto de ruina y devastación a la comarca en cuestión. No obstante, el triunfo de uno de los bandos hace posible el devenir histórico. El derramamiento de sangre permite pensar una nueva época o un nuevo capítulo; el proceso histórico no es posible sin ella. La imaginación histórica de Ponce de León organiza un relato antagónico, su obra dice:

A pesar de esto se logró en 1810 hacer las paces con los bárbaros gracias a las acertadas medidas que se tomaron para perseguirlos, gastándose fuertes sumas, y los apaches permanecieron sin inquietar a la provincia durante 20 años, hasta 1831, en cuya fecha sus nuevas correrías lanzaron a la ruina al ya independiente estado de Chihuahua (Ponce de León, 1905: 20).

La historia de Chihuahua, en Ponce de León, se basó en la construcción de una trama histórica dotada de elementos dramáticos que la complejizan en un alto grado. En este punto, no hay duda de la naturaleza ideológica y poética de la obra en análisis. $\mathrm{Su}$ estructura partió de una serie de situaciones inciertas que obstaculizaban el andar del proceso histórico en Chihuahua, las cuales debían ser encaradas por el protagonista y de ellas salir vencedor. En su conjunto, los capítulos presentan estos obstáculos para el protagonista de manera frecuente, y logran la conexión con otros bajo una narración lógica e inteligible.

Añadiendo a la interpretación de la obra su contenido y forma, resulta en la confrontación de fuerzas antagónicas. El largo combate inició con el colonizador europeo contra el bárbaro, siguió el insurgente contra el español, continuó con el mexicano contra el invasor norteamericano, y en sus últimas etapas, se enfrentó el liberal contra el conservador. Pero a pesar de que cada uno de los capítulos presenta a su respectivo enemigo a vencer, existe un mal perenne en la narración, a veces visto a simple vista, otras latente y oculto, resulta ser pues el denominado indio bárbaro. 
Es este personaje el que habitó desde un tiempo inmemorial el territorio en cuestión y no pudo ser vencido sino hasta la década de 1880 por el chihuahuense decimonónico, dirigido este por una elite civilizada, liberal y de ascendencia blanca, arquetipo del héroe de la trama de Ponce de León.

Como fue dicho en párrafos superiores, la obra fue resultado de un encargo del propio gobernador Enrique C. Creel. Por ende, se puede inferir que hay un intento de su autor por complacer a su mecenas, que resultaba ser miembro de la familia más poderosa y adinerada del estado de Chihuahua, los Terrazas-Creel. Tanto fue el interés de escribir amable y delicadamente de sus patrocinadores, que en el capítulo número VI, titulado "La Reforma", Ponce de León menciona los actos heroicos que Luis Terrazas dirige al confrontar la amenaza conservadora en Chihuahua con el inicio de la Guerra de los Tres Años. La batalla determinante de esta guerra para el autor fue la de la Labor de Terrazas, efectuada en el año de 1860, y donde el bando liberal triunfante era comandado por el Gral. Luis Terrazas. Los acontecimientos fueron narrados de esta manera en Las Reseñas:

El triunfo de la Labor fue decisivo, los conservadores no pudieron rehacerse y el partido del progreso se consolidó para siempre, debiéndose este resultado, como fue dicho en un impreso de aquella época al Sr. D. Luis Terrazas que en menos de quince días reunió la fuerza vencedora y se dio a conocer venciendo a la reacción como consta a todos los chihuahuenses que lo vieron entrar triunfante a la cabeza de los valientes ciudadanos que lo eligieron como jefe (Ponce de León, 1905: 416) (énfasis del autor).

Leer las citas hace evidente la postura política e ideológica que su autor tenía en un determinado momento. Hubo ciertas cargas estructurales y circunstanciales que lo llevaron a imaginar y tramar el pasado chihuahuense de la presente manera. En las últimas páginas continuó su escritura a favor de Luis Terrazas y su causa, también, arguyó sobre los esfuerzos que el estado de Chihuahua libró para vencer al conservadurismo y los méritos ad- 
quiridos por la patriótica acción. Para Ponce de León (1905), no es posible imaginar la instauración de la república federal sin la labor heroica de los chihuahuenses; fue determinante para la construcción de su presente. En el texto se dice:

El estado de Chihuahua durante la guerra de Reforma fue el único que con sus propios recursos venció en su seno a la reacción que tan solo treinta días pudo dominar en su territorio y a pesar del aniquilamiento en el que se hallaba, por la terrible guerra con los bárbaros, pudo varias veces remitir artillería y pertrechos de guerra para auxiliar a los constitucionalistas de Nuevo León y Durango, y tropas suyas tomaron honrosa parte en el sitio y toma de Guadalajara, en Irapuato, Mazatlán, Poncitlán, Atenquique y Zacatecas (p. 417).

Ponce de León en esta última mención esclareció su visión acerca del Chihuahua del siglo XIX, su construcción del tiempo pasado, de una época anterior a la que vivió y en la que distinguió la existencia de un estado de aniquilamiento ocasionado por la guerra contra los bárbaros. Es aquí donde se observa el latente enemigo del chihuahuense que siempre de una u otra forma se manifiesta en la historia.

Al continuar con el análisis de las obras de comienzos del siglo $\mathrm{XX}$, es necesario identificar el hito que pone fin a la época caótica y antigua y da paso, o posibilidad, a una nueva y moderna. Es entonces requisito desenmarañar de qué forma el proceso llevó a ese punto. Para tal cometido será utilizado el texto del intelectual Federico García y Alva titulado Álbum directorio del estado de Chihuahua, obra escrita y publicada en los años de 1903 a 1904, misma que fue una petición personal del oligarca Luis Terrazas para hacer promoción del estado de Chihuahua. No está de más decir que el Álbum directorio tuvo la intención de ser un panfleto de promoción ideológica de la familia Terrazas-Creel para difundir su idea de modernidad y civilidad de Chihuahua.

En sus páginas existe un apartado que tiene por nombre "El Chihuahua antiguo”. Resulta ser este capítulo una narración sobre lo que el autor considera los acontecimientos más trascendentales 
de la historia regional. Se identificaron cinco eventos, el primero de ellos, la Independencia de México y el fusilamiento del cura Miguel Hidalgo; segundo, la Intervención francesa y la itinerante república juarista por el territorio estatal; tercero, el asesinato del liberal Donato Guerra; cuarto, la batalla de Tres Castillos; último, la rebelión de Tomochic. Lo característico de estos eventos incluidos en el apartado del Chihuahua antiguo, es que compartieron esta visión de un pasado caótico, repleto de obstáculos y adversidades, con enemigos a combatir por medio de acciones violentas y militares. Esa era la visión que se tenía en ese momento de lo que era el pasado de Chihuahua.

Al referirse en específico al combate de Tres Castillos y la guerra contra los bárbaros, Federico García y Alva comienza su relato con las hostilidades desarrolladas a mediados del siglo XVIII entre españoles y apaches. La visión de este pasado, de nuevo, refirió a una época violenta y de "desoladoras correrías que debían durar un siglo aniquilando a los habitantes de estas entonces desventuradas regiones" (García y Alva, 1904: 28). Con esto, una vez más se expone la construcción discursiva de un tiempo antiguo nefasto, donde la posibilidad de superarlo y entrar a una nueva etapa no podía ser posible hasta eliminar de una vez por todas al nómada, ya que este lo único que ocasionaba era arruinar propiedades e impedir todo progreso (García y Alva, 1904: 28).

En este proceso histórico y civilizatorio de la historia de Chihuahua, el apache fundamentalmente era determinado por su naturaleza vil y salvaje. En todas las construcciones narrativas del pasado se encuentra. Misma estructura discursiva sostiene el proceso civilizatorio y el ingreso a una nueva temporalidad. Para García y Alva (1904), la audacia maléfica de los apaches era tal que en algún momento:

Llegaron a urdir en esta capital una conspiración para exterminar a los blancos; pero fueron descubiertos por el capitán general Neve y ahorcados y descuartizados 24 de los principales cabecillas, sofocándose con tan violentas medidas el levantamiento que se preparaba (p. 28). 
El año de 1880, y en particular la batalla de Tres Castillos, son para García y Alva los puntos cruciales en el desarrollo histórico de la región. El triunfo del coronel Joaquín Terrazas sobre el grupo apache al mando del jefe Victorio, marcó el hito y el comienzo de una época sin la cuota de sangre que por años se cobró a los habitantes del estado de Chihuahua. Ahí se encuentra el punto de quiebre temporal que distingue dos épocas; el chihuahuense terracista ubicó el comienzo de su época con el triunfo de la batalla de Tres Castillos. En palabras de Federico García y Alva (1904):

...las precauciones parecían inútiles y todos los esfuerzos infructuosos, recorriendo el más temible de los jefes indios, el famoso Victorio, la región boreal de Chihuahua señalando su paso con el incendio, el pillaje y la matanza, escapando a la incesante persecución del más activo, valeroso y conocedor de los jefes que han hecho la guerra a los bárbaros: el coronel Joaquín Terrazas, que por fin logró en "Tres Castillos" (Distrito Bravos) exterminar a Victorio y a su gavilla obteniendo el triunfo que no consiguieron los soldados de la Unión Americana con cuantiosos elementos, y de tal trascendencia que marcó el hasta aquí a las invasiones y libertó a Chihuahua del tributo de sangre y de riqueza que pagaba a los insaciables enemigos de la raza blanca (p. 29) (énfasis del autor).

Hasta el momento, Tres Castillos resultó ser el acontecimiento que segmentó el devenir histórico. Es la medida con la que las narraciones históricas de la época se configuraron y el sentido de las mismas no pueden entenderse sin él. Pero no solo esta obra dota de un significado trascendental al combate pues, al igual que esta, el texto titulado Guerra contra los apaches. Las memorias del coronel Joaquín Terrazas argumenta que el combate trajo consigo una experiencia novedosa.

Este libro, al igual que los otros dos, se publicó en el periodo terracista, en el año 1905. A grandes rasgos, contiene el recuerdo de las vivencias del coronel al mando de las campañas militares contra los bárbaros. Pero más allá del ejercicio memorístico de Joaquín Terrazas, el valor del documento recae en la valorización 
que los editores hicieron de las acciones del militar. En su prólogo se hizo mención de lo importante que fue su esfuerzo por combatir a los indios nómadas, y que por tanto, los niños y futuras generaciones debían conocer al hombre que instauró el tiempo próspero y progresivo en el que vivieron. Al respecto, los editores dijeron en el año de 1905:

Los niños hoy, los niños de mañana, los hombres pacíficos dedicados al trabajo que ha de transformar y defender a nuestra Patria, haciéndola próspera, deben saber a quiénes deben la paz, quiénes hicieron posible el progreso (Terrazas, 1906: 11).

La cita superior refleja la idea compartida de la época; los logros del coronel Terrazas y sus aliados, sus triunfos sobre los conservadores, franceses y apaches hicieron posible el proceso civilizatorio. El Chihuahua de la época pasada fue descrito en la obra como un lugar aislado y lejano del centro político, siendo flagelado en cada momento por el azote del bárbaro. También hay espacio en el texto para exacerbar el orgullo regional, asegurándose que si los chihuahuenses triunfaron sobre los nómadas, fue gracias solo a la voluntad heroica de los habitantes del estado y no al apoyo de la federación. Puesto que resulta fundamental para el argumento, se coloca esta cita acerca la época superada:

Chihuahua, aislado del centro del país durante tantos años, con tantas dificultades para comunicarse con el resto de la federación, sufriendo el flagelo constante de una raza salvaje que impedía el progreso, y recibiendo perjuicios más bien que beneficios con su dependencia del Gobierno Federal, ha dado mayores pruebas, de patriotismo, ha hecho mayores esfuerzos por salvar a la unión, que muchos otros estados centrales, en que no había esas dificultades para recibir los beneficios del centro ni esas circunstancias para sufrir más reveses.

Las Memorias del coronel Terrazas pretendieron ser para sus editores la muestra fehaciente de que se había superado una épo- 
ca e ingresado a otra. La construcción discursiva del tiempo se presenta en más de una ocasión, ya que la historia regional, según ellos, se dividió en dos épocas y cuya conexión entre ambas era el chihuahuense de cambio de siglo (Terrazas, 1906: 12). En sus últimas páginas, el libro rinde un homenaje a Terrazas donde se asegura que si la civilización se instauró en Chihuahua fue gracias a él. Los últimos párrafos dicen:

Hubiéramos querido que aquel viejo venerable llevara sobre su frente un letrero que dijera: 'yo soy Joaquín Terrazas. Yo he gastado mi vida abriéndole el camino a la civilización. Por mí hay ferrocarriles' (Terrazas, 1906: 164).

Las tres interpretaciones narrativas del pasado antes referenciadas son frascos en cuyo interior se vaciaron los valores ideológicos de los sujetos que las escribieron. Las obras preservan un aura que transmite los sentires y la atmósfera del tiempo en que fueron redactadas. En su análisis comparten tipologías que las vuelven muy similares entre sí: fueron escritas en la misma época y en los mismos años, estuvieron estrechamente relacionadas a la familia oligarca Terrazas-Creel y su estructura configura los eventos del pasado bajo la misma coherencia.

En cuanto a sus contenidos, se presenta la historia y el proceso histórico regional en función del proceso civilizatorio, representado entre la civilización y la barbarie. El triunfo de la civilización sobre el bárbaro marcó un parteaguas en el devenir del tiempo, asegurando la existencia de varias épocas y justificando el presente que vivieron los autores.

El tiempo desde ellas se configura de manera experiencial. Los sucesos vividos en la guerra contra los nómadas sirvieron como justificaciones para moldear el tiempo de cierta manera. Es así que el tiempo se presenta como una construcción social, con temporalización, segmentación o división. La batalla de Tres Castillos y el triunfo del civilizado sobre el bárbaro sirvió como un punto de referencia temporal para indicar un cambio en la experiencia que el tiempo daba a los individuos. 
Al sumar valor a tales interpretaciones del pasado, se encuentra también el desarrollo del proceso civilizatorio. Los relatos en su conjunto muestran las calamidades que la instauración de la civilización, traída en principio por el hombre blanco y continuada por el chihuahuense decimonónico, enfrentó al verse en una región inhóspita habitada por los nómadas. El apache dentro de las tramas fue dotado de cualidades animales y así fue convertido en el enemigo del hombre civilizado, a la cual se le debía de combatir en diferentes etapas del proceso.

\section{EL PROCESO CIVILIZATORIO EN EL “CRIOLLO” DE FUENTES MARES, SEGÚN LUIS ABOITES}

El proceso civilizatorio en la historiografía de Chihuahua se presenta como una especie de tipología compartida en las obras históricas de la primera mitad del siglo XX. En el apartado anterior se expone que las visiones escritas en los albores del siglo pasado se construyeron a partir de la estructura de la supuesta lucha de la civilización contra la barbarie, y cuyas formas parecen perpetuarse en autores de la mitad del mismo siglo. En su afamado artículo “José Fuentes Mares y la historiografía del norte de México. Una aproximación desde Chihuahua (1950-1957)”, Luis Aboites identifica los elementos más característicos de dicha forma de escritura de la historia. Entre ellos resalta la idea del desierto como escenario principal de la historia chihuahuense, y factor determinante de la idiosincrasia regional. No obstante, el elemento del desierto en los relatos antes revisados no juega un papel de importancia, casi no es mencionado. En todo caso, lo que sí es observable es el recurso de escribir sobre la lejanía de Chihuahua en relación con el centro país.

Otro elemento clave de la historiografía de Fuentes Mares, según Aboites, es el llamado personaje del criollo chihuahuense. En el texto puede leerse acerca del papel que juega la supuesta ausencia de mestizaje de la población de Chihuahua argumentada por Fuentes Mares en sus obras. El criollo plenamente relacionado a un origen español y una tradición occidental, es el factor que 
construye el norte progresista e industrial de Fuentes Mares. El artículo dice:

Un rasgo que retoma Fuentes Mares para argumentar sobre las singularidades del país llamado Chihuahua es la población. En este caso el argumento más nítido: la población Chihuahuense es distinta a la de otros lados porque es esencialmente criolla (Aboites, 2000: 482).

La postura historiográfica de Fuentes Mares es cuestionada por Aboites en su texto, aludiendo al trabajo de historia demográfica y buscando respuestas en ella. A pesar de esto, es claro que "el criollo" de Fuentes Mares responde a su declarada hispanofilia y catolicismo. En diferentes escritos José Fuentes Mares expresó su apreciado hispanismo y su pensamiento religioso como categorías de análisis, solo es necesario mencionar el inicio de su tesis doctoral publicada bajo el nombre de Kant y la evolución de la conciencia socio-política moderna, donde elaboró una crítica al pensamiento kantiano desde una visión hispánica y católica, lugar social e histórico que denunció desde el principio de su libro (Fuentes, 2000: 6).

La civilización para Fuentes Mares se representa entonces por el avance del espíritu hispano por América; su conquista y el aglutinamiento de diferentes pueblos indígenas en una sola cultura. Parafraseando el texto del filósofo Jorge Ordóñez Burgos acerca del pensamiento filosófico sobre la historia en Fuentes Mares, la civilización occidental representada por España, adentró a la América indígena en el devenir civilizatorio (Ordóñez, 2019: 162). Pensado por Fuentes Mares como un proceso un tanto distinto al anglosajón o germánico, no lo es para Norbert Elias, ya que el proceso civilizatorio responde a un mismo origen histórico y geográfico. Recordando líneas superiores, la idea de civilización surge en las cortes europeas, y de ahí fue replicada en diferentes sociedades.

Ahora, visto como un rasgo compartido o heredado por la historiografía de Chihuahua, la lucha entre civilización contra la barbarie se mantiene constante en los relatos históricos del siglo 
XX. Occidente, representado por el español conquistador, o bien, el hombre blanco, llega a tierras hostiles y barbáricas en pos de civilizarlas. Al respecto, solo basta la comparativa entre el texto de Ponce de León escrito en el año de 1905 y el libro Monterrey... de José Fuentes Mares, escrito en 1976. Ambos comienzan de una forma muy similar: el hombre blanco llegando al norte de México en busca de riquezas y gloria. Casi como si se hubiese copiado de la obra de Ponce de León, Fuentes Mares (1976) en Monterrey inicia:

Solo el afán de gloria para su nombres y su fortuna para su casa pudo empujar al hombre blanco por este mundo de tribus belicosas, climas extremados y relices que dibujan sus crestas entre el cielo y los tostados pastizales. Solo un corazón denodado pudo inducirle al cuantioso certamen de aventuras sin paralelo, a un Ponce de León que persigue la Fuente de la Juventud, el más codiciado de los tesoros; a un Vazquez de Coronado que encuentra en el Gran Cañón mientras busca las Siete Ciudades Legendarias...(p. 9).

Al continuar con el análisis hecho por Luis Aboites a la obra de Fuentes Mares, también es observable la constancia del proceso civilizatorio en la historiografía del siglo XX. La observación da lugar a conjeturar si el interpretar de tal forma el proceso civilizatorio de Chihuahua responde a un modelo heredado, donde particularmente, el antagonismo se presenta entre el nómada (barbárico) y el hombre blanco o criollo (civilizado) más que la fórmula presentada entre el liberal mexicano (civilizado) contra el conservador (barbárico) en las interpretaciones del centro del país. Dicha postura da pie a seguir pensando el desarrollo de una historiografía que propone un distanciamiento o una identidad particular del norte de México con respecto al sur-centro en Fuentes Mares y que Aboites identifica. Acerca del combate entre el civilizado y el bárbaro en Chihuahua en la historiografía de Fuentes Mares, dice Aboites (2000): 
Tal elemento es el carácter épico de la historia local, el de la lucha contra el desierto y contra la barbarie; la lucha del blanco 'civilizado' contra la crueldad de los indios 'salvajes' pero también -y esto es muy importante- contra el 'centro' y 'sur' del país (p. 486).

Escribir la historia de tal forma, es interpretado por Luis Aboites como un modelo de la elite local, en donde se ensalzan los logros del Chihuahuense emprendedor que llega a batallar a una tierra hostil en todo sentido. Tal estilo de escritura de Fuentes Mares lo lleva también a enfrentarse intelectualmente con otro conocido historiador chihuahuense, Francisco R. Almada, quien a diferencia del primero, optó por una forma de escritura de la historia "oficialista" carente del elogio a las elites y donde se buscaban las similitudes entre norte y centro del país, más que las diferencias (Aboites, 2000: 503).

La confrontación intelectual entre ambos recayó sobre todo en la interpretación y valorización de algunos de los personajes más trascendentales de la historia local. Luis Terrazas, Ángel Trías y Benito Juárez fueron objeto de análisis para ambos historiadores. El elogio a Luis Terrazas por Fuentes Mares fue duramente criticado por Almada, acusándolo de omisiones. Almada publicó obras que, por la contra, rescataban las acciones realizadas por liberales como Ángel Trías y defendían la figura del “indio" Juárez de la crítica hispanofílica de Fuentes Mares. Las posturas historiográficas de ambos responden, en la opinión de Aboites, al origen de las mismas, la de Fuentes Mares es la historia criolla relacionada al patrocinio de los grandes capitalistas y la segunda es la historia oficial de los gobiernos posrevolucionarios (Aboites, 2000: 498-501).

En lo que respecta al proceso civilizatorio en la historiografía de Fuentes Mares, es válido entenderlo como una tipología heredada, presente desde los autores chihuahuenses de principio del siglo XX y obviamente también resultado de su orgullosa hispanofilia. También parece ser una de las formas utilizadas por lo que Aboites llama "la historia de las elites". El elemento se presenta en la historiografía de Fuentes Mares y en obras de principio del siglo XX tales como la de Ponce de León y la de Federico García y Alva. 
Comparten las tres que fueron solicitudes de las elites en sus respectivos momentos. Asimismo, otro de los elementos compartidos es la relevancia que juega la lucha del civilizado contra la barbarie. Parece ser tan importante que el mismo Fuentes Mares en su libro Y México se refugió en el desierto escribió que la batalla de Tres Castillos era el punto final del capítulo más importante de la historia del norte de México: las guerras indias (Fuentes, 1953: 154).

\section{PARA TERMINAR}

Del presente escrito surgen las siguientes aseveraciones. La primera es sin duda la forma en que el proceso civilizatorio es interpretado en parte de la historiografía chihuahuense. Ante todo, opera bajo la estructura de civilización enfrentando a la barbarie, personificadas la primera en el hombre blanco occidental y la segunda en el amerindio nómada. La estructura observada en las obras de inicios del siglo XX trasciende y se presenta en José Fuentes Mares, autor chihuahuense de mediados de siglo.

Es muy probable que dicha visión de la historia chihuahuense responda, tal como lo menciona Luis Aboites en su artículo, a una especie de tipología propia de la historiografía de la elite regional. Tanto los trabajos de Fuentes Mares como los de Ponce de León y García Alva fueron encargos de los grupos dominantes en sus respectivos momentos. Asimismo, la llamada operación historiográfica de Michel de Certeau abogaría por deducir lo mismo, ya que propone la existencia de un "lugar social" desde donde el historiador escribe sus textos.

Otra de las aseveraciones es la similitud de valorizaciones hechas sobre el pasado. Para evitar el juicio de un trabajo simplista o tendencioso se recurrió al estudio de diferentes obras, donde fue posible seguir la presencia de elementos compartidos. De entre ellos resaltan el triunfo de los chihuahuenses sobre los nómadas en la década de 1880, y sobre todo, cómo la batalla de Tres Castillos significó la pauta para distinguir un antes y un después. Es luego de estos sucesos, según los textos revisados, que fue posible 
hablar y pensar acerca de civilización y civilidad en las regiones chihuahuenses.

\section{BIBLIOGRAFÍA}

Aboites Aguilar, L. (2011). Historia breve de Chihuahua. México: FCE.

---. (2000). “José Fuentes Mares y la historiografía del norte de México. Una aproximación desde Chihuahua (1950-1957)”. Historia Mexicana, XLIX (3), 477-507.

Alonso, C. (1989). "Civilización y barbarie”, Hispania, 72(2), 256-263. Cosío Villegas, D. (1999). El Porfiriatio. Vida política interior. Primera Parte. México: Editorial Clío.

Elias, N. (2016). El proceso de la civilización. México: FCE.

Dale Lloyd, J. (2001). Cinco ensayos sobre la cultura material de rancheros y medieros del noroeste de Chihuahua. México: UIA.

--- (1987). Proceso de modernización capitalista en el noroeste de Chihuahua, 1880-1910. México: UIA.

De Certeau, M. (2010). La escritura de la historia. México: UIAITESO.

Del Arenal Fenochio, J. (2006). Juárez de Don Justo Sierra. Juárez, su obra y su tiempo de Justo Sierra. México: Editorial Miguel Ángel Porrúa.

Fuentes Mares, J. (1976). Monterrey una Ciudad creadora y sus capitanes. México: Jus.

---. (2000). Kant y la evolución de la conciencia socio-política moderna. México: UACH.

---. (1953). Y México se refugió en el desierto. México: Jus.

García y Alva, F. (2003). Álbum directorio del estado de Chihuahua (facsímil). México: Gobierno del estado de Chihuahua.

Guerra, F. X. (1989). Del Antiguo Régimen a la Revolución. MéxiCO: FCE.

Herrera, A. L. y Cicero, R. E. (1895. Catálogo de la colección de Antropología del Museo Nacional. México: Imprenta del Museo Nacional. 
León García, R. y González Herrera, C. (2000). Civilizar o Exterminar, Tarahumaras y apaches en Chihuahua, siglo XIX. México: CIESAS-INI.

Ordóñez Burgos, J. (2019). “Fuentes Mares y la filosofía de la historia”, Chihuahua Hoy, año 17, núm. 17, 139-138.

Ponce de León, J. M. (2003). Reseñas históricas del estado de Chihuahua (facsímil). México: Gobierno del estado de Chihuahua. Terrazas, J. (1989). Memorias del Coronel Joaquín Terrazas. México: Centro Librero La Prensa.

Zermeño Padilla, G. (2017). Historias conceptuales. México: El Colegio de México.

Wasserman, M. (2003). Capitalistas, caciques y revolución, la familia Terrazas en Chihuahua (1854-1911). México: Centro Librero La Prensa.

\section{ARCHIVOS}

Área de Colecciones Especiales de la Secretaría de Cultura de Chihuahua.

Hemeroteca digital de la Universidad Nacional Autónoma de México. 